This manuscript has been authored by UT-Battelle, LLC under Contract No. DE-AC0500OR22725 with the U.S. Department of Energy. The United States Government retains and the publisher, by accepting the article for publication, acknowledges that the United States Government retains a non-exclusive, paid-up, irrevocable, world-wide license to publish or reproduce the published form of this manuscript, or allow others to do so, for United States Government purposes. The Department of Energy will provide public access to these results of federally sponsored research in accordance with the DOE Public Access Plan(http://energy.gov/downloads/doe-public-access-plan). 


\title{
Crystallographic texture in an additively manufactured nickel-base superalloy
}

\author{
Dong $\mathrm{Ma}^{1, *}$, Alexandru D. Stoica ${ }^{1}$, Zhuqing Wang ${ }^{2}$, Allison M. Beese ${ }^{2, *}$ \\ ${ }^{1}$ Chemical and Engineering Materials Division, Neutron Sciences Directorate, Oak Ridge \\ National Laboratory, Oak Ridge, Tennessee 37831, USA \\ ${ }^{2}$ Department of Materials Science and Engineering, Pennsylvania State University, University \\ Park, PA 16802, USA \\ *Emails: dongma@ornl.gov and amb961@psu.edu
}

\begin{abstract}
Laser-based directed energy deposition was used to additively manufacture a wall out of pre-alloyed powder of a nickel-base superalloy-Inconel 625 . The crystallographic texture of the wall has been characterized using neutron diffraction and electron backscatter diffraction. The measured pole figures show a strong Goss texture component $(\{011\}<100>)$ plus a comparatively much weaker cube component $(\{001\}<100>)$, both indicating that the $<100>$ direction of the majority of grains lies along the laser-scanning direction (or the length direction). The origin of the Goss texture is hypothesized to be a result of the preferential $<100>$-oriented dendritic solidification driven by the laser-induced heat flow which is affected by the combined effect of laser power, absorption of powder, and laser scanning speed. The texture-induced mechanical softening is also presented. This study aids in understanding the processingstructure-property relationship in additive manufacturing.
\end{abstract}

Keywords: Texture; Inconel 625; Superalloy; Additive manufacturing; Neutron diffraction. 


\section{Introduction}

Nickel-base superalloys are of particular interest to numerous industries, including the aerospace industry, due to their high strengths and high creep resistance at high temperatures. Among these, Inconel 625 (IN625) is a solid-solution strengthened alloy and is attractive for fabrication by additive manufacturing (AM), owing to the high cost of fabricating its components through traditional subtractive manufacturing methods [1, 2].

Additive manufacturing using metallic powder is a rapidly growing technology in which near-net shape components are built a layer at a time by the deposition, melting, and fusion of subsequent layers of material [3]. In laser-based directed energy deposition (DED), metal powder feedstock is delivered to the desired location through a nozzle that is coaxial with a laser. The laser melts the powder and creates a melt pool in the material below. As the laser advances, the melt pool cools and the metal solidifies and fuses to the layer below. As subsequent layers are deposited to build up a 3D component, the surrounding metal of the part is subjected to rapid thermal cycles, which results in microstructures drastically different from those in wrought counterparts. As such, understanding the influence of AM processing on microstructure and mechanical properties is essential for qualification of the AM process, enabling future engineering designs to take advantage of these new techniques. The present study has focused on neutron diffraction characterization of crystallographic texture present in an IN625 wall made by laser-based DED, as well as the texture-induced mechanical anisotropy.

\section{Materials and Methods}

\subsection{Processing by additive manufacturing}

In the present study, a $101 \mathrm{~mm}$ long, $28 \mathrm{~mm}$ tall, $7 \mathrm{~mm}$ thick IN625 wall was deposited by laser-based DED, with pre-alloyed IN625 powder, onto an annealed Inconel 625 (AN IN625) 
substrate plate (measuring $152.4 \mathrm{~mm}$ long, $38.1 \mathrm{~mm}$ wide and $12.7 \mathrm{~mm}$ thick) [4]. A laser power of $2 \mathrm{~kW}$ (IPG Photonics YLR-12000) with a scanning speed of $10.6 \mathrm{~mm} / \mathrm{s}$ was used to deposit the powder, which was delivered by a cladding head (Precitec YC-50) at a powder feed rate of $16 \mathrm{~g} / \mathrm{min}$ in an argon gas flow of $9.4 \mathrm{~L} / \mathrm{min}$. The wall was constructed from 3-bead wide depositions (or 3 passes) for each layer, with a bead thickness of $\sim 0.89 \mathrm{~mm}$ and a step-over of $\sim 2.29 \mathrm{~mm}$. The deposition direction changes based on layer number, with even numbered layers deposited in the opposite direction of odd numbered layers. All three passes within a single layer were deposited along the length direction. More details of the AM process have been described elsewhere [5].

The spherical IN625 powder were made by gas atomization and sieved using $-100 /+325$ meshes, providing a powder diameter range from 44 to $149 \mu \mathrm{m}$. The elemental compositions of the IN625 powder are listed in Table 1, and the AM IN625 wall is schematically shown in Figure 1, with respect to three orthogonal directions along the height (H or HD), the thickness (T or TD) and the length ( $\mathrm{L}$ or $\mathrm{LD})$, respectively.

Table 1. Nominal composition (wt.\%) of Inconel 625 used for Additive Manufacturing.

\begin{tabular}{|c|c|c|c|c|c|c|}
\hline $\mathrm{Ni}$ & $\mathrm{Cr}$ & $\mathrm{Mo}$ & $\mathrm{Fe}$ & $\mathrm{Nb}+\mathrm{Ta}$ & $\mathrm{Co}$ & $\mathrm{Mn}$ \\
\hline 59.78 & 21.51 & 8.75 & 4.58 & 3.49 & 0.28 & 0.26 \\
\hline & & & & & & \\
\hline $\mathrm{Si}$ & $\mathrm{Ti}$ & $\mathrm{Al}$ & $\mathrm{C}$ & $\mathrm{P}$ & $\mathrm{S}$ & \\
\hline 0.25 & 0.24 & 0.19 & 0.027 & $<0.005$ & $<0.002$ & \\
\hline
\end{tabular}




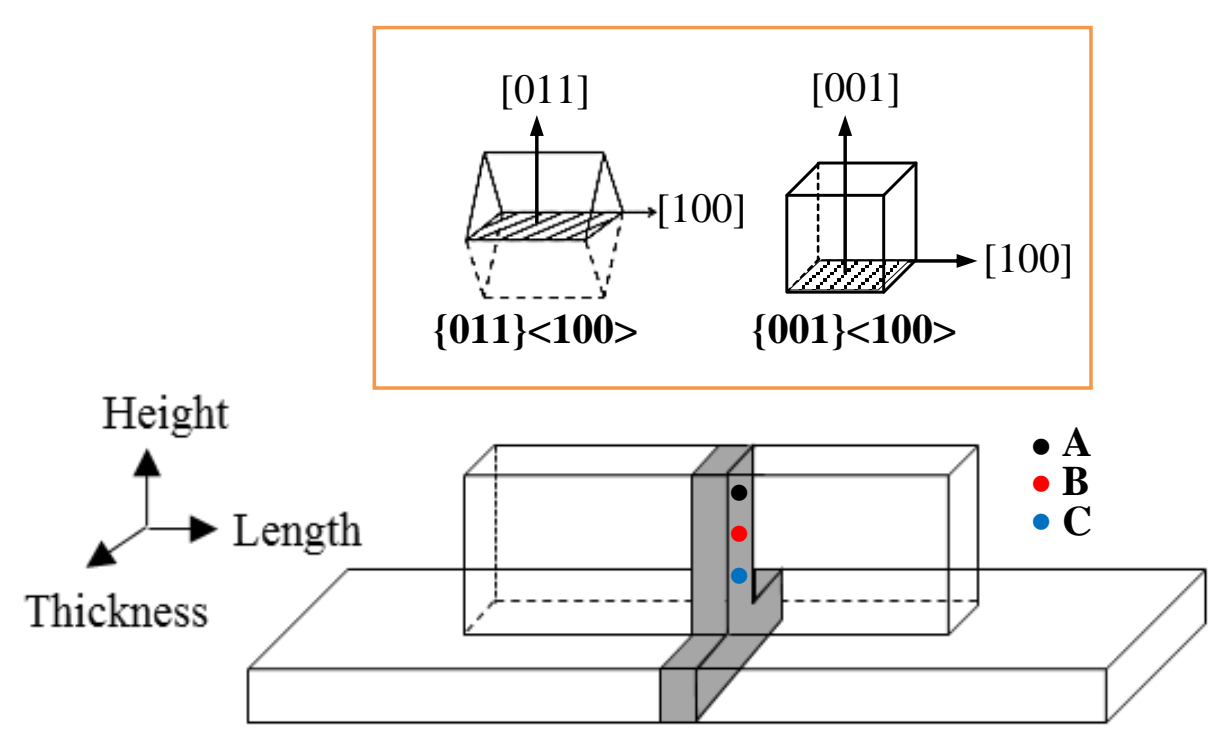

Figure 1. Schematic of the IN625 wall made by laser DED on top of an IN625 substrate plate. The shaded region was removed from the wall and substrate for characterization of texture. Letters (A, B and C) mark the locations where texture was measured by neutron diffraction. The top inset shows the Goss texture component $(\{011\}<100>)$ and the cube texture component $(\{001\}<100>)$ with respect to the sample coordinate system.

\subsection{Microstructural characterization}

For microstructural evaluation, the samples extracted from the annealed IN625 substrate plate and from the as-deposited AM-IN625 wall were polished using standard metallographic procedures. These samples were examined in a scanning electron microscope (SEM, FEI Quanta 200). Electron backscatter diffraction (EBSD) was used to determine grain sizes, orientations, and shapes in a random cross-section of annealed IN625 and in three cross-sections of AMIN625 which are normal to the LD, TD and HD, respectively.

\subsection{Texture characterization by neutron diffraction}

As shown by the shaded region in Figure 1, a representative $\sim 7.0 \mathrm{~mm}$ thick slice was extracted from the AM IN625 wall. Texture characterization was conducted at three depths with 
respect to the top of the wall, which are $7 \mathrm{~mm}$ apart and marked as $\mathrm{A}, \mathrm{B}$ and $\mathrm{C}$. Time-of-flight neutron diffraction characterization of the texture was carried out on VULCAN, the Engineering Diffractometer at the Spallation Neutron Source, Oak Ridge National Laboratory [6]. VULCAN has two detector banks, centered at scattering angles of $-1+90^{\circ}$ to the incident neutron beam, enabling simultaneous measurements of two perpendicular scattering vectors. More details of VULCAN's instrumentation and experimental setup can be found elsewhere [7, 8].

In order to obtain full pole figures, two orthogonal rotations of the sample were implemented by the sample stage and a goniometer (HROT) attached to the stage. In the present measurement, the rotation about the vertical axis, $\Omega$, was conducted through the sample stage by a step of $5^{\circ}$ ranging from $\pm 45^{\circ}$ to $\pm 90^{\circ}$ with respect to the incident beam, while the horizontal rotation, $\Phi$, was implemented by the HROT goniometer by a step of $30^{\circ}$ ranging from $0^{\circ}$ to $360^{\circ}$. The piece extracted from the AM IN625 wall (see Fig. 1) was centered onto a holder with the wall thickness direction parallel to the HROT's rotation axis. A total of 120 sample positions $(\Omega$, $\Phi)$ were measured with a neutron data collection time of 2 minutes for each position. GSASbased single-peak fitting was used to obtain integrated intensities of selected reflections (or poles) in each diffraction pattern. Pole figures were then obtained by representing the integrated peak intensities, after appropriate normalization as well as corrections of sample absorptions and sampling volumes for each sample position, as a function of the polar coordinates $(\chi, \varphi)$ that are converted from corresponding $(\Omega, \Phi)$ with respect to each detector bank $[9,10]$.

\subsection{Mechanical deformation}

Cylindrical specimens (5 $\mathrm{mm}$ diameter and $10 \mathrm{~mm}$ long) were extracted using wire electrical discharge machining (EDM) from the AM-IN625 wall (at the depth similar to that of 
Location A) with the cylinder axis lying along the LD, as well as from the annealed IN625 substrate plate. These specimens were compressed at a strain rate of $\sim 2.5 \times 10^{-5} \mathrm{~s}^{-1}$ at room temperature using a MTS load frame with a pair of high-density alumina platens. Engineering strains were calculated from the relative cross-head displacements after corrections of the machine compliance. The samples were not polished for mechanical testing. The ends of the samples were machined with milling in order to ensure that the end faces of the EDM-cut samples are parallel and perpendicular to the load axis. Carbon films were applied between each end surface and the platen, which served as a lubricant during deformation to minimize barreling.

Compression tests provide us with a large available plastic strain regime before localization compared with tension. Compression tests also provide a uniform stress state, as opposed to bending, which would result in a gradient of stress states across the gage section. The specimen aspect ratio of 2:1 and the applied strain rate are commonly used for compression tests to avoid buckling and barreling. Therefore, compression testing provides us with a uniform large deformation range for studying plastic deformation up to a plastic strain of $\sim 10 \%$.

\section{Results}

Figures 2(a), 2(b) and 2(c) depict three typical EBSD maps of AM IN625 obtained from cross-sections perpendicular to the TD, HD and LD, respectively, indicative of elongated grains with a high aspect ratio ranging from 2.5 to 4.3 and preferred orientations. In comparison, Fig. 2(d) shows an EBSD map of annealed IN625 obtained from a random cross-section, indicative of equiaxed grains with much smaller sizes and randomly distributed orientations. 

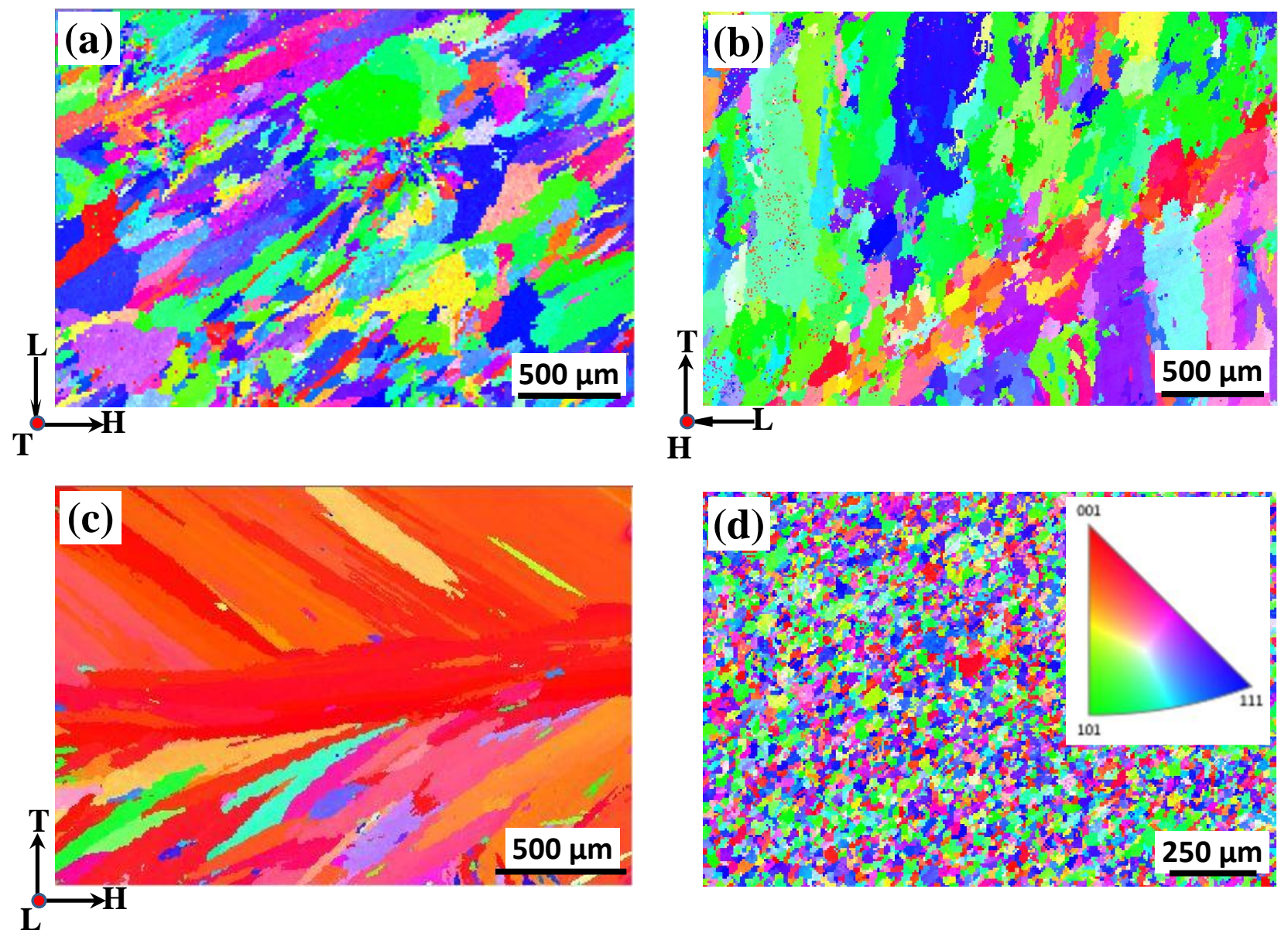

Figure 2. EBSD maps of (a) the cross-section (near location A) whose normal is parallel to the thickness (T) direction of AM-IN625, (b) the cross-section (near location A) whose normal is parallel to the height $(\mathrm{H})$ direction of AM-IN625, and (c) the crosssection (near location B) whose normal is parallel to the length (L) direction of AMIN625 and (d) a representative cross-section of annealed IN625. In all plots, the colors represent the $h k l$ plane normals coming out of the page. 
Figure 3 shows the (200), (220) and (111) pole figures determined for locations A, B and C, with HD being aligned to the center of the pole figures while LD and TD are the horizontal and vertical axes, respectively. Using an identical intensity color scale for each type of pole figure, Fig. 3 demonstrates dramatic strengthening of texture as deposition advances from location $\mathrm{C}$ to A. For identification of the texture components, both HD-centered and LD-centered pole figures for location $\mathrm{A}$ are presented in Fig. 4, where the ideal pole locations of the $\{011\}<100>$ (Goss) texture are marked as filled circles. The observed texture maxima match very well with the ideal Goss distribution of poles, indicating that, within a small angular deviation, the predominant texture component at location A is of Goss type. For instance, this is clearly visible in the HD-centered (220) pole figure which shows a texture maximum in the center, indicative of $\langle 110>/ / \mathrm{HD}$, while in the LD-centered (200) pole figure, the presence of a strong maximum in the center indicates $<100>/ / \mathrm{LD}$. An additional weak component can be also identified, which is attributed to the minority $\{100\}<001>$ (Cube) texture component, as marked as red crosses in Fig. 4.

The texture features characteristic of location A are significantly reduced toward locations B and C. Figure 5 illustrates in more details the HD-centered and LD-centered pole figures corresponding to location C. Broader fiber type features are evident in the HD-centered pole figures. The central texture maxima of the (200) and (220) pole figures suggest $<100>$ as the fiber axis. For comparison, the ideal locations of $\{100\}<001>$ (Cube) texture components are also included in Fig. 5. It can be concluded that the <100> //HD fiber encompasses a rather large angular range of crystallographic directions around $<100>$ while the Goss component still has an important contribution. 

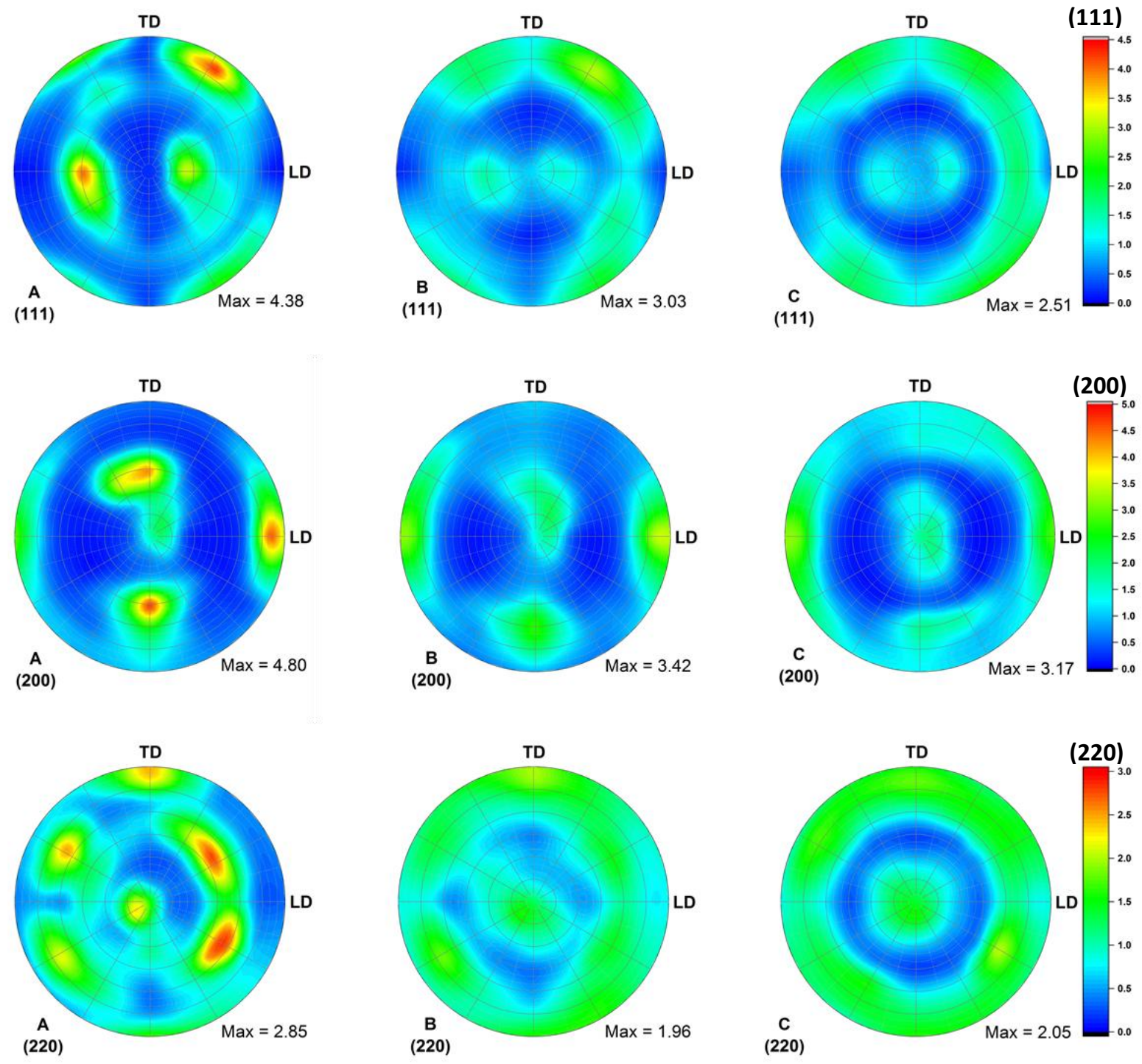

Figure 3. (111), (200) and (220) pole figures of the AM build determined for locations $\mathrm{A}, \mathrm{B}$ and $\mathrm{C}$, respectively. $\mathrm{LD}$ denotes the length direction, $\mathrm{TD}$ is the thickness direction, and the center of the pole figures is the height direction (HD). 

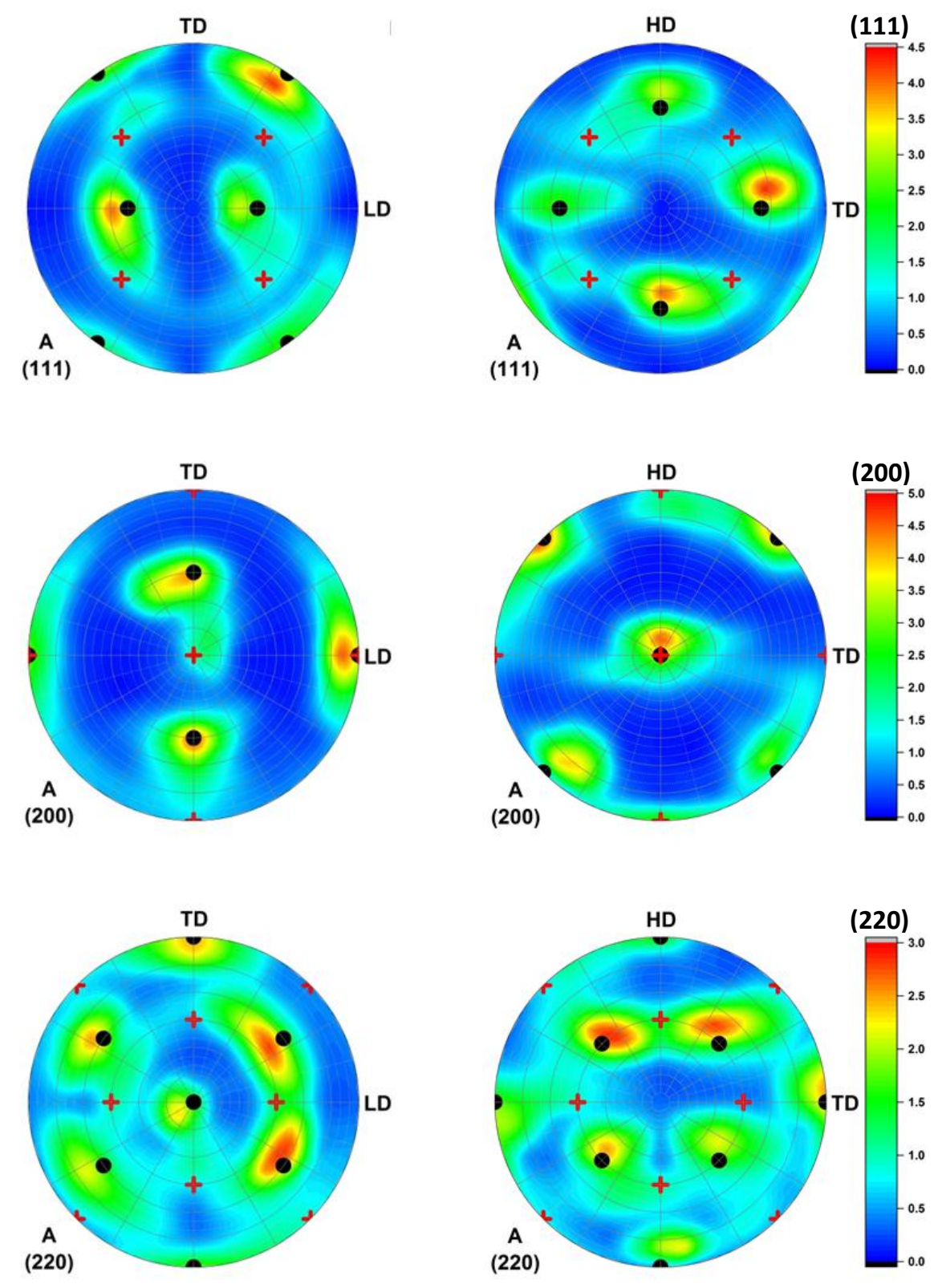

Figure 4. (111), (200) and (220) pole figures determined at location A, being centered on HD (left columns) and LD (right columns), respectively. Filled circles denote the $\{011\}<100>$ (Goss) texture component, and red crosses represent the $\{001\}<100>$ (Cube) texture component. 

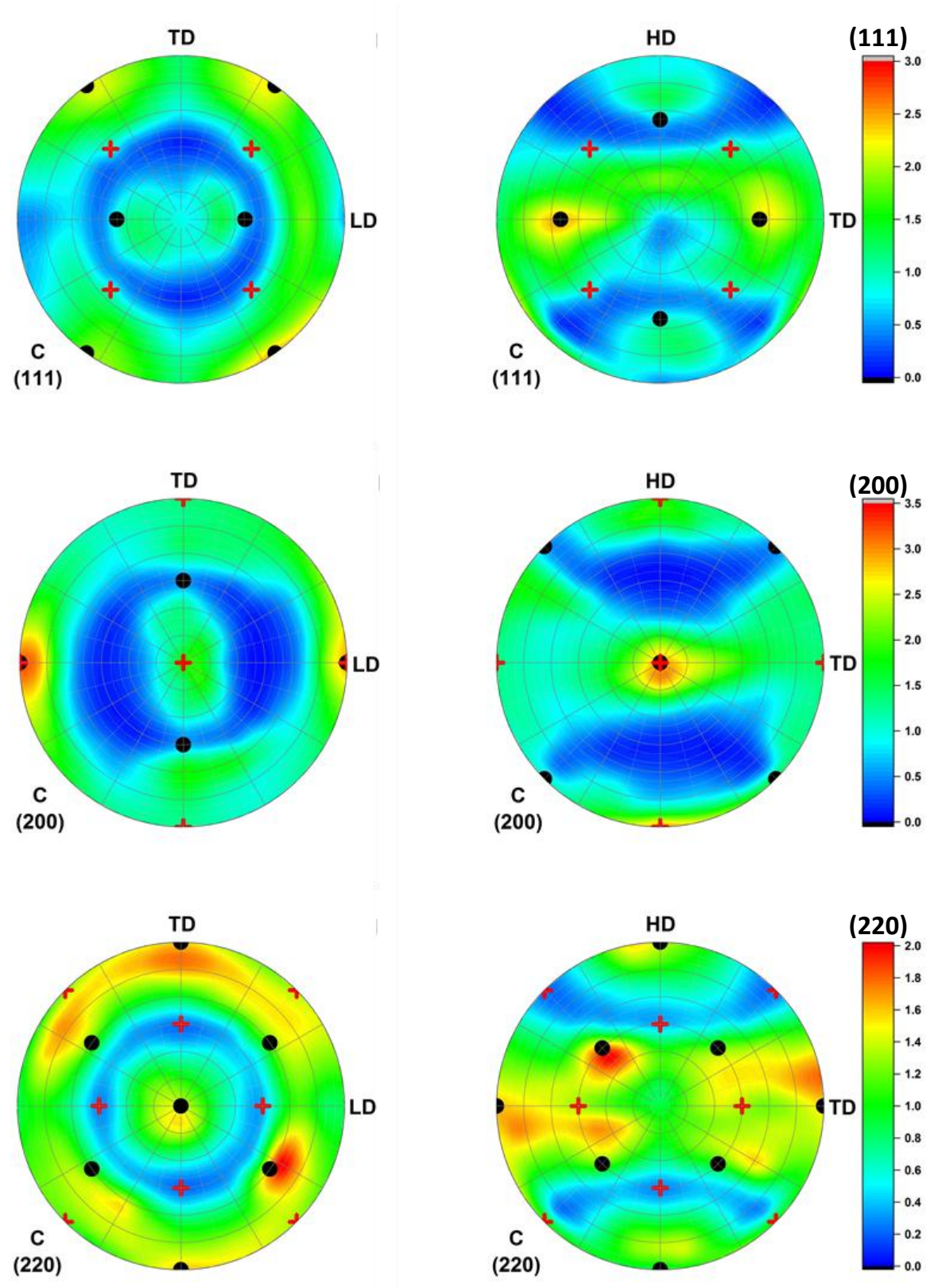

Figure 5. (111), (200) and (220) pole figures determined at location C, being centered on HD (left columns) and LD (right columns), respectively. Filled circles denote the $\{011\}<100>$ (Goss) texture component, and red crosses represent the $\{001\}<100>$ (Cube) texture component. 


\section{Discussion}

Table 2 provides a summary of the texture components observed in Inconel 718 (IN718) and IN625 made by two types of AM techniques, i.e., laser-based DED and electron beam freeform fabrication $\left(\mathrm{EBF}^{3}\right)$. While the Goss component observed in IN625 in the present study is consistent with that in IN718 made by $\mathrm{EBF}^{3}$ as reported by Tayon et al. [11], it is distinctly different from that of the rotated cube texture component found in both IN718 and IN625 also made by laser-based DED [12, 13]. As pointed out by Dinda et al. [13] and Wei et al. [14], the rotated cube texture was due to the formation of zigzag-shaped <100>-oriented columnar grains across neighboring layers that underwent alternating forward and backward depositions; these preferentially oriented grains resulted from the $<100>$-oriented primary dendritic solidification driven by the heat flow, which was generated by the advancing of laser-melted pool and was aligned at $\sim 45^{\circ}-60^{\circ}$ to the substrate or previous deposited layers. In contrast, the Goss component observed in AM IN625 in the present study indicates that, during solidification, columnar dendrites grew along one of the $<100>$-directions that was nearly parallel to the laserscanning direction while the other two $<001>$ directions are aligned at $\sim 45^{\circ}$ to the substrate. Accordingly, the heat flow direction in the present AM case is distinctly different from that of aligning at $\sim 45^{\circ}-60^{\circ}$ to the laser scanning direction as reported by Dinda et al. [13] and Wei et al.[14]. In what follows, we hypothesize that the combined effects of laser power, absorption of powder, and laser scanning speed affect the predominant direction of heat flow which drives dendritic growth, accounting for solidification texture variations.

While there is no single parameter that can capture the differences in thermal history between additively manufactured components made using different processing parameters and conditions, a typical method for comparing studies is to compute the linear heat input used. The 
linear heat input is defined as the laser power divided by the scanning speed. However, given that the present study used a Nd:YAG laser, and the studies in [12-14] used a $\mathrm{CO}_{2}$ laser, the actual energy available to melt the substrate (or effective energy input) would differ for the same linear heat input because the absorptivity of $\mathrm{Ni}$ for these two laser wavelengths differs. As shown in Table 2, the absorptivity of a $\mathrm{CO}_{2}(\lambda=10.6 \mu \mathrm{m})$ is significantly lower than that of Nd:YAG laser $(\lambda=1.06 \mu \mathrm{m})$, meaning that, for the same linear heat input, less of the energy from a $\mathrm{CO}_{2}$ laser is absorbed by the solid material, therefore, there is a lower effective energy input. Additionally, while the absorptivity of electron beams is not well defined, photons are either reflected or absorbed within a few nanometers of the surface of a material, while the kinetic energy of electrons is deposited a few $\mu \mathrm{m}$ below the surface of a material, indicating a more efficient transfer of energy in EBM versus laser deposition [15].

Based on the work by Wei et al. [14], the angle, $\theta$, between the heat flow direction, which is nearly opposite to the <100>-dendritic growth direction, and the laser scanning direction at the solid-liquid interface can be written as: $\cos \theta=\frac{\frac{\partial T}{\partial x}}{\sqrt{\left(\frac{\partial T}{\partial x}\right)^{2}+\left(\frac{\partial T}{\partial z}\right)^{2}}}$, where $T$ is temperature, $x$ and $z$ are the axes pointing to the laser scanning direction and the build height direction, respectively, $\frac{\partial T}{\partial x}$ is the partial temperature gradient along the laser scanning direction and $\frac{\partial T}{\partial z}$ is the partial temperature gradient along the height direction. As inferred from the threedimensional heat transfer and material flow model and simulations by Manvatkar and DebRoy [16], the increase in laser power and absorptivity of powder at the same scanning speed leads to the increase in the rate of heat input (i.e., effective energy input), increasing the pool depth/volume, thus reducing $\frac{\partial T}{\partial z}$. On the other hand, a higher laser scanning speed at the same 
efficient energy input increases $\frac{\partial T}{\partial x}$. As such, $\theta$ is reduced significantly in our case with respect to those reported by Dinda et al. [12, 13] and Wei et al. [14], due to the application of much higher efficient energy input and higher scanning speed, causing the <100>-dendritic growth more inclined to the laser scanning direction and resulting in the Goss texture. Another factor affecting the heat flow direction is the dependency of $\frac{\partial T}{\partial z}$ on the position (or height) of the deposition layers, with subsequent or higher-level layers exhibiting smaller $\frac{\partial T}{\partial z}$, owing to the increased temperature of the build; this may explain why the Goss component at location A is much stronger than those at locations $\mathrm{B}$ and $\mathrm{C}$.

Multi-pass depositions used in the present study may also contribute to the difference in the heat flow direction, especially along the thickness direction. In addition, the weak cube texture component present in AM IN625 may also originate from the application of multi-passes, which produced $<100>$-oriented dendrites/grains sandwiched between two neighboring passes but elongated along the HD, as shown in Fig. 2(c).

As mentioned above, the cylindrical compression sample of AM IN625 was cut at a depth similar to that of Location A such that the axial axis was parallel to the length direction of the AM IN625 wall. Thus, the majority of the grains, belonging to either the Goss or the Cube component, were aligned along the sample-axial axis, forming essentially a <100>-type fiber texture with respect to the loading axis during the compression tests. As pointed out by Chin and Mammel [17], for $\{111\}<110>$ slip in the axisymmetric flow case, fiber textures near the <100> orientation are expected to be $\sim 50 \%$ weaker than for orientations near $\langle 111\rangle$ and/or $\langle 110\rangle$, as a result of having much smaller Taylor factors for grains whose plane normals are near the <100> orientation. This largely explains why, when comparing with the texture-free, annealed IN625, the AM-IN625 samples exhibit a smaller yield stress as well as a lower work-hardening rate, as 
determined from the stress-strain curves in Fig. 6 and listed in Table 3. The $\langle 100\rangle$ texture in AM-IN625 also accounts for the decrease in Young's modulus, which is 27\% smaller than that of annealed IN625 [18]. The texture also drastically affects the thermomechanical stability of AM IN625 when plastically deformed at elevated temperatures [19].

Table 2. Comparison of textures observed in IN718 and IN625 made by AM.

\begin{tabular}{|c|c|c|c|c|c|c|c|}
\hline $\mathrm{AM}$ & Alloy & $\begin{array}{l}\text { Laser } \\
\text { Type \& } \\
\text { Power }\end{array}$ & $\begin{array}{c}\text { Scan } \\
\text { Speed } \\
(\mathrm{mm} / \mathrm{s})\end{array}$ & Absorptivity & $\begin{array}{l}\text { Effective } \\
\text { energy } \\
\text { input } \\
(\mathrm{J} / \mathrm{mm})\end{array}$ & Texture & Ref. \\
\hline $\begin{array}{l}\text { Laser- } \\
\text { DED }\end{array}$ & IN718 & $\begin{array}{c}\mathrm{CO}_{2} \\
750 \mathrm{~W}\end{array}$ & 6.25 & $0.05-0.15 \dagger$ & $\sim 12$ & $\begin{array}{l}\text { Rotated cube } \\
{[011] / / \mathrm{HD}} \\
{[01 \overline{1}] / / \mathrm{LD}} \\
{[100] / / \mathrm{TD}}\end{array}$ & {$[13,14]$} \\
\hline $\begin{array}{l}\text { Laser- } \\
\text { DED }\end{array}$ & IN625 & $\begin{array}{c}\mathrm{CO}_{2} \\
900 \mathrm{~W}\end{array}$ & 5.0 & $0.05-0.15 \dagger$ & $\sim 18$ & $\begin{array}{l}\text { Rotated cube } \\
{[011] / / \mathrm{HD}} \\
{[01 \overline{1}] / / \mathrm{LD}} \\
{[100] / / \mathrm{TD}}\end{array}$ & [12] \\
\hline $\begin{array}{l}\text { Laser- } \\
\text { DED }\end{array}$ & IN625 & $\begin{array}{c}\text { Nd:YAG } \\
2,000 W\end{array}$ & 10.6 & $0.15-0.35 \dagger$ & $\sim 47$ & $\begin{array}{l}\text { Goss (predominant) } \\
+ \text { cube (weak) } \\
\text { Goss }-\{011\}<100> \\
{[011] / / \mathrm{HD}} \\
{[100] / / \mathrm{LD}} \\
{[01 \overline{1}] / / \mathrm{TD}} \\
\text { Cube }-\{001\}<100> \\
{[001] / / \mathrm{HD}} \\
{[100] / / \mathrm{LD}} \\
{[010] / / \mathrm{TD}}\end{array}$ & $\begin{array}{l}\text { This } \\
\text { work }\end{array}$ \\
\hline $\mathrm{EBF}^{3}$ & IN718 & $\begin{array}{l}\text { High- } \\
\text { power } \\
\text { Electron } \\
\text { Beam }\end{array}$ & 32 & - & - & $\begin{array}{l}\text { Goss }-\{011\}\langle 100\rangle \\
{[011] / / \mathrm{HD}} \\
{[100] / / \mathrm{LD}} \\
{[01 \overline{1}] / / \mathrm{TD}}\end{array}$ & [11] \\
\hline
\end{tabular}

$\dagger$ Data from Ref. [20] 


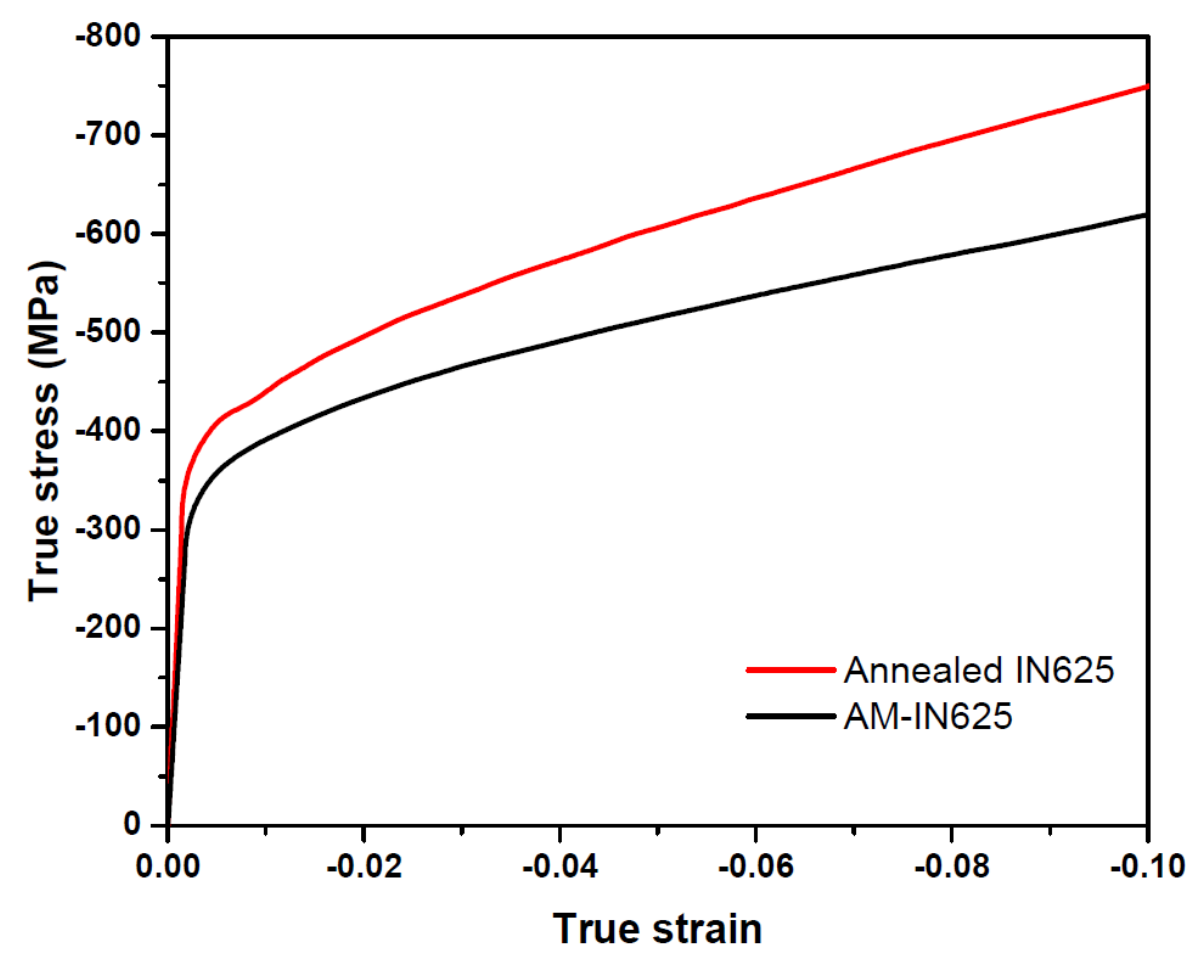

Figure 6. True stress-strain curves of AM IN625 and annealed IN625 determined under compression at room temperature.

Table 3. Comparison of mechanical properties between AM IN625 and annealed IN625.

\begin{tabular}{|c|c|c|c|}
\hline & $\begin{array}{c}\text { Young's Modulus } \\
(\mathrm{GPa})\end{array}$ & $\begin{array}{c}\text { Yield Strength } \\
(0.2 \% \text { offset, MPa) }\end{array}$ & $\begin{array}{c}\text { Work-hardening rate* } \\
\text { (MPa per 1\% strain) }\end{array}$ \\
\hline AM-IN625 & $152 \pm 8$ & $352 \pm 18$ & $21.5 \pm 0.2$ \\
\hline Annealed IN625 & $207 \pm 11$ & $395 \pm 20$ & $29.8 \pm 0.3$ \\
\hline
\end{tabular}

*Value determined between plastic strains of $3 \%$ and $10 \%$. 


\section{Summary and Conclusions}

Crystallographic texture in an additively manufactured Inconel 625 superalloy has been characterized by neutron diffraction and EBSD, showing that:

(1) A Goss component $(\{011\}<100>)$ is predominant, originating from solidification of $<100>$-oriented dendrites/grains driven by the high power laser-induced heat flow, which is locally perpendicular to the laser scanning direction while aligned at $45^{\circ}$ to the substrate or previous-deposited layers.

(2) A comparatively much weaker cube component $(\{001\}<100>)$ is also present, whose magnitude varies depending on the depths of deposited layers from the substrate.

(3) Both texture components contribute to $\langle 100\rangle$-oriented grains preferentially lying along the length direction, giving rise to significant texture-induced softening in comparison with its texture-free counterpart (annealed IN625). 


\section{Acknowledgments}

The authors gratefully acknowledge the financial support of the National Science Foundation through award number CMMI-1402978. Any opinions, findings, and conclusions or recommendations expressed in this material are those of the authors and do not necessarily reflect the views of the National Science Foundation. AMB acknowledges funding from the Oak

Ridge Associated Universities Ralph E. Powe Junior Faculty Enhancement Award. AM-IN625 samples were fabricated at Penn State's Center for Innovative Materials Processing through Direct Digital Deposition (CIMP-3D). A portion of this research at ORNL's Spallation Neutron Source was sponsored by the Scientific User Facilities Division, Office of Basic Energy Sciences, U.S. Department of Energy. We thank Matthew Frost for technical support. 


\section{References}

[1] F. J. Xu, Y. H. Lv, Y. X. Liu, F. Y. Shu, P. He, and B. S. Xu, Microstructural Evolution and Mechanical Properties of Inconel 625 Alloy during Pulsed Plasma Arc Deposition Process, J. Mater. Sci. Technol., 29 (2013) 480-488.

[2] M. Rombouts, G. Maes, M. Mertens, and W. Hendrix, Laser metal deposition of Inconel 625: Microstructure and mechanical properties, J. Laser Appl., 24 (2012) 052007.

[3] J. Laeng, J. G. Stewart, and F. W. Liou, Laser metal forming processes for rapid prototyping - a review, Int. J. Prod. Res., 38 (2000) 3973-3996.

[4] INCONEL ${ }^{\circledR}$ alloy 625, Spec. Met. Corp. SMC-020., (2006).

[5] E. R. Denlinger, J. C. Heigel, P. Michaleris, and T. A. Palmer, Effect of inter-layer dwell time on distortion and residual stress in additive manufacturing of titanium and nickel alloys, J. Mater. Process. Technol., 215 (2015) 123-131.

[6] K. An, H. D. Skorpenske, A. D. Stoica, D. Ma, X. L. Wang, and E. Cakmak, First In Situ Lattice Strains Measurements Under Load at VULCAN, Metall. Mater. Trans. A-Phys. Metall. Mater. Sci., 42A (2011) 95-99.

[7] G. M. Stoica, A. D. Stoica, M. K. Miller, and D. Ma, Temperature-dependent elastic anisotropy and mesoscale deformation in a nanostructured ferritic alloy, Nat. Commun., 5 (2014) 2019-2029.

[8] T. Ungar, A. D. Stoica, G. Tichy, and X. L. Wang, Orientation-dependent evolution of the dislocation density in grain populations with different crystallographic orientations relative to the tensile axis in a polycrystalline aggregate of stainless steel, Acta Mater., 66 (2014) 251261.

[9] G. M. Stoica, and A. D. Stoica, The experimental procedures to measure pole figures and inverse pole figures at VULCAN, ORNL Report, to be published. 
[10] G. M. Stoica, A. D. Stoica, K. An, D. Ma, S. C. Vogel, J. S. Carpenter, and X. L. Wang, Extracting grain-orientation-dependent data from in situ time-of-flight neutron diffraction. I. Inverse pole figures, J. Appl. Crystallogr., 47 (2014) 2019-2029.

[11] W. A. Tayon, R. N. Shenoy, M. R. Redding, R. K. Bird, and R. A. Hafley, Correlation Between Microstructure and Mechanical Properties in an Inconel 718 Deposit Produced Via Electron Beam Freeform Fabrication, J. Manuf. Sci. Eng.-Trans. ASME, 136 (2014) 061005

[12] G. P. Dinda, A. K. Dasgupta, and J. Mazumder, Laser aided direct metal deposition of Inconel 625 superalloy: Microstructural evolution and thermal stability, Mater. Sci. Eng. AStruct. Mater. Prop. Microstruct. Process., 509 (2009) 98-104.

[13] G. P. Dinda, A. K. Dasgupta, and J. Mazumder, Texture control during laser deposition of nickel-based superalloy, Scr. Mater., 67 (2012) 503-506.

[14] H. L. Wei, J. Mazumder, and T. DebRoy, Evolution of solidification texture during additive manufacturing, Sci Rep, 5 (2015) 16446.

[15] T. E. Everhart, and P. H. Hoff, DETERMINATION OF KILOVOLT ELECTRON ENERGY DISSIPATION VS PENETRATION DISTANCE IN SOLID MATERIALS, J. Appl. Phys., 42 (1971) 5837.

[16] V. Manvatkar, A. De, and T. DebRoy, Spatial variation of melt pool geometry, peak temperature and solidification parameters during laser assisted additive manufacturing process, Mater. Sci. Technol., 31 (2015) 924-930.

[17] G. Y. Chin, and W. L. Mammel, COMPUTER SOLUTIONS OF TAYLOR ANALYSIS FOR AXISYMMETRIC FLOW, Transactions of the Metallurgical Society of Aime, 239 (1967) 1400.

[18] Z. Wang, A. D. Stoica, D. Ma, and A. M. Beese, Diffraction and single-crystal elastic constants of Inconel 625 at room and elevated temperatures determined by neutron diffraction, Mater. Sci. Eng. A-Struct. Mater. Prop. Microstruct. Process., 647 (2016) 406-412.

[19] A. M. Beese, Z. Wang, A. D. Stoica, and D. Ma, to be published. 
[20] M. F. Modest, Laser-Material Interaction, in LIA Handbook of Laser Materials Processing (Chapter 5). Eds.: Reedy and Farson, Laser Institute of America, 2001. 